\title{
Fin del mundo: Una mirada sobre la paradoja de la identidad cultural chilena
}

\author{
Hans Ulrich Gumbrecht
}

Stanford University

\begin{abstract}
Resumen: A través de textos del Inca Garcilaso de la Vega y Heinrich von Kleist, de Alonso de Ercilla y María Graham y de Mistral, Neruda y Teillier, el autor, como un observador externo, sondea qué hay detrás de la idea de Chile como "fin del mundo", y en qué medida la relación o la distancia con este concepto transmite una forma de los chilenos de habitar — en el sentido de Heidegger — su territorio.

Palabras clave: fin del mundo, Chile, Patagonia, Heidegger, Inca Garcilaso, Kleist, Ercilla, María Graham, Mistral, Neruda, Teillier.
\end{abstract}

\section{THE WORLD'S END: A LOOK AT THE PARADOX OF CHILEAN CULTURAL IDENTITY}

AвSTRAct: Drawing on the texts of Inca Garcilaso de la Vega and Heinrich von Kleist, of Alonso de Ercilla and Maria Graham and of Gabriela Mistral, Pablo Neruda and Jorge Teillier, the author approaches Chile as an outside observer to probe beneath the idea of the country as the "world's end" and the extent to which engagement or otherwise with this concept conveys a way in which Chileans dwell, in Heidegger's sense, in their territories.

Keywords: world's end, Chile, Patagonia, Martin Heidegger, Inca Garcilaso de la Vega, Heinrich von Kleist, Alonso de Ercilla, Maria Graham, Gabriela Mistral, Pablo Neruda, Jorge Tellier.

Hans Ulrich Gumbrecht. Crítico literario y filósofo alemán. Doctor por la Universidad de Constanza y profesor emérito del Departamento de Literatura Comparada, Francés e Italiano, de la Universidad de Stanford. Email: sepp@stanford.edu. 
$\mathrm{H}$

ace aproximadamente diez años, cuando por primera vez viajé a Chile por más de un par de días, me sorprendió - y confundió en alguna medida - la presencia masiva de la expresión "fin del mundo" como motivo de autorreferencia nacional. Incluso, la pequeña tienda de mi hotel ubicado en el centro de Santiago estaba llena de poleras, tazones, bufandas y postales que tenían inscritas esas palabras. Había escuchado ocasionalmente esa denominación en otros países del hemisferio sur, como en Australia o Nueva Zelandia, pero en esos lugares la expresión apunta, con una cierta autoironía, a un sentimiento de lejanía, cuya posible melancolía se conjuga por el mero hecho de expresarlo de manera explícita. A pesar de que este mismo gesto melancólico existe en Chile, su rasgo específico e intelectualmente interesante en el Pacífico sudoccidental estriba en sus marcadas implicancias afirmativas. Una "Universidad Finis Terrae", como aquella fundada en Santiago hace un par de décadas, es inconcebible en otra cultura, pues sólo en Chile el "fin del mundo" tiene el sello inequívocamente positivo que requiere el nombre de una institución académica.

Resulta sorprendente, pues, para un observador foráneo y empático, comprobar el uso recurrente de esta fórmula autorreferente por parte de chilenos de todos los grupos etarios y niveles sociales que integran esta sorprendente y bellamente formal sociedad; un uso con conocimiento vago de su posible ambigüedad. Cuando se les pregunta a qué pueden referirse esas palabras de manera específica y precisa, la mayoría de ellos, en el típico tono eufemístico nacional, se inclina por una connotación irónica o por desestimarlas implícitamente. Por contraste, cuando en una conversación con un connotado historiador chileno insistí en que una expresión supuestamente insignificante no podía tener una resonancia tan fuerte y sostenida, decidimos organizar un seminario para analizar su significado, el cual de hecho terminé dictando en Santiago a inicios de 2018 para estudiantes de la Universidad Adolfo Ibáñez y la Universidad de Stanford. Basándome en las discusiones surgidas durante ese evento académico, procuraré desarrollar una tesis sobre esa paradoja oculta en la identidad cultural de Chile. 
Si bien, a mi entender, el tema relativo al "fin del mundo" nunca ha sido abordado con seriedad, sí ha surgido de manera ocasional y lateral en debates más amplios sobre las diversas formas de experiencia "nacional", causadas por la localización y la forma geográfica de Chile. En un ensayo publicado hace una década y media, el historiador Rafael Sagredo Baeza sostiene, primero, que desde el siglo XVIII un sentimiento de gratitud colectiva por la "protección natural" que brindaba el territorio acompañó la prehistoria y las primeras décadas de la República de Chile, para luego criticar cómo una percepción más extasiada del mismo espacio como "Jardín del Edén" se transformó en una legitimación para diferentes tipos de autoritarismo político (a través de asignarse la responsabilidad de cultivar este supuesto regalo divino).

Una marcada autocrítica nacional parece haber sido tan obligada y dominante entre los intelectuales chilenos durante décadas que ya no parece generar ningún tipo de polémica y, por ende, tampoco debates intelectuales productivos. En cambio, las reacciones resultan más interesantes cuando las críticas provienen del exterior y gatillan eventuales instintos de autodefensa nacional. Un caso relevante fue la polémica entre el filósofo italiano Ernesto Grassi y su joven colega chileno Juan Rivano, que se prolongó desde 1959 hasta 1964. Desde 1951, Grassi, un discípulo italiano de Martin Heidegger que, por decir lo menos, nunca se esmeró en esconder su simpatía con el régimen de Mussolini, era invitado todos los años a dictar un seminario sobre metafísica en la Universidad de Chile. Esta experiencia (que incluyó visitas a países sudamericanos vecinos) fue la base para un ensayo publicado en 1959 bajo el título "Assenza di Mondo". En él, bajo el concepto filosófico de la "ausencia de mundo" y en un tono europeo muy condescendiente, Grassi criticó lo que a su parecer constituía una falta de "historia y de mundo" en la relación de los sudamericanos con sus territorios.

Resaltando con orgullo su filiación con el marxismo, como correspondía al canon intelectual de la generación posterior a Grassi, Juan Rivano, en 1964, respondió a "Assenza di Mondo" con el texto "La América ahistórica y sin mundo del humanista Ernesto Grassi”, en el que evocaba toda suerte de iniciativas industriales y proyectos científicos a través de los cuales, en su opinión, los chilenos habían comenzado a hacer uso de sus recursos nacionales como base para un progreso eco- 
nómico y, al menos según Rivano, también social. Hasta cierto punto, y de manera casi tragicómica, el elogio del carácter pragmático de los chilenos con respecto a su territorio debe haber confirmado a cabalidad lo que Grassi tanto criticaba.

Para comenzar, no resulta fácil entender a qué se refería exactamente Grassi con la frase "ausencia de mundo e historia". Puede que haya sido una reacción al contraste entre la cultura chilena y la italiana, y cómo esta última, hasta hoy, se caracteriza por una relación muy marcada entre ciertos lugares y momentos específicos en la historia de Roma y de Italia. Más compleja es la sospecha de que la tesis de Grassi acerca de una "ausencia de historia" en Chile, por una razón específicamente filosófica, se refiere, desde otro punto de vista, a lo que podría denominarse como una "ausencia de estética" en relación con el paisaje nacional. Por "estética" quiero referirme a cualquier relación con el mundo como entorno material que, a diferencia del análisis racional de la naturaleza a través de conceptos y argumentos propios de la temprana modernidad, incluye un componente sensual, es decir, un componente relacionado con el cuerpo. Distinto de la visión histórica del mundo, tal como surgió en Europa Central entre 1780 y 1830, el concepto de historia de Grassi estaba basado de manera clara y explícita en Giambattista Vico, en cuyo - pre e incluso anticartesiano- pensamiento una relación con el mundo pasado todavía no excluía el cuerpo ni los sentidos (como sucedería poco después con la visión histórica del mundo). Podía, por lo tanto, en nuestro lenguaje, contener la dimensión estética como algo integrado con preocupaciones pragmáticas y prácticas. Entonces, lo que Grassi debe haber extrañado en América del Sur era no sólo una relación histórica con el mundo, sino que también, dentro de la relación histórica existente, una relación explícita y separadamente estética con el mundo.

Pero si bien la reacción de Rivano sólo vino a confirmar el prejuicio de Grassi acerca de una actitud excesivamente racional y pragmática hacia sus territorios — reacción que, además, no provocó ningún debate ulterior-, yo quisiera valerme, para efectos de nuestra discusión sobre "el fin del mundo", de dos preguntas inherentes a esta confrontación de hace más de medio siglo. Primero, ¿habrá acaso Grassi (y, con él, Rivano) pasado por alto alguna dimensión no pragmática de este país y, por ende, difícil de pesquisar, acerca de la forma en que los chi- 
lenos se refieren a su tierra? Y segundo, si esa dimensión no pragmática efectivamente existiera, ¿podría estar asociada a la ubicación y forma específica de la geografía de Chile?

$* * * *$

Desde un punto de vista filosófico, esas interrogantes, al igual que varios problemas relativos al espacio de la existencia humana, resultan mucho menos superficiales o incluso inofensivas de lo que pueden parecer a primera vista. En términos fenomenológicos, el espacio, como la dimensión que se desarrolla en torno al cuerpo humano, ha sido radicalmente ignorado por la filosofía occidental en su foco casi exclusivo en la conciencia y el tiempo, como la estructura mental básica, desde la temprana modernidad (en ese sentido, la sentencia proverbial de Descartes "cogito ergo sum" resulta emblemática). Es interesante observar de qué forma una nueva apreciación sensual, vale decir "estética", del "paisaje" surge a partir del siglo XVIII, precisamente, porque comenzó a ser la excepción frente a un uso predominantemente racional y práctico del territorio. En otras palabras y formulado como una paradoja: sólo por el hecho de transformarse en un elemento periférico y aislado, la relación sensual ("estética") con el espacio y el concepto de "paisaje" lograron captar la atención filosófica.

La crítica reiterada y a ratos sorprendentemente violenta que hace Martin Heidegger de la filosofía de Descartes está sobre todo motivada por lo que él considera como una omisión del espacio en el pensamiento cartesiano. Podemos, pues, afirmar que el punto de inflexión decisivo a partir del cual Heidegger comenzó a desarrollar su trayectoria fecundamente excéntrica en la filosofía occidental, en su libro Ser y tiempo de 1927, estaba marcado por la reintegración de la dimensión somática (en otras palabras, corpórea) de la existencia, en contraste con la noción de "sujeto" meramente basada en la conciencia como autorreferencia humana. El nuevo concepto clave era Dasein, como sustituto de sujeto y su referencia especial (y, por ende, corpórea) se hacía visible con la partícula $D a$ - (que significa "ahí” en alemán), que trasladaba el sentido de la vida humana hacia un "estar ahí'. Una de las más importantes distinciones resultantes de esta divergencia con la tradición filosófica es el contraste elaborado por Heidegger entre el 
"simple estar presente" (Vorhandenheit) y el "estar a la mano" en el sentido de "ser utilizable" (Zuhandenheit), como dos actitudes radicalmente diferentes del Dasein respecto del entorno material (que incluye otros cuerpos humanos). Así como el "simple estar presente" es sinónimo del paradigma sujeto/objeto en el cual la conciencia humana se encuentra fuera ("Vor", "delante") de la materialidad del mundo, separada ontológicamente de él y basándose en un análisis racional a través de conceptos abstractos, el "estar a la mano" presupone una relación de inclusión entre Dasein y el mundo físico —Dasein es parte del mundo físico-, debido a la recuperación del espacio y del soma en ese concepto. El Dasein, es decir, la existencia humana como existencia corpórea, es concebido como una entidad que habita el mundo y, por lo tanto, como tal, "siempre de antemano" familiarizada con lo que necesita saber del mundo. Es esta familiaridad con el mundo propio lo que esta noción de "estar a la mano" resalta.

Mucho más adelante en su vida y su obra, Heidegger elaboró una versión del "estar a la mano" más específicamente relacionada con el espacio. Me refiero a su ensayo Construir habitar pensar, en el que, en un planteamiento que puede parecer sorprendente en un primer momento, insiste en la prioridad del habitar sobre el construir. Con el "habitar" Heidegger se centra en la relación primordial entre Dasein y el espacio que precede (o al menos debiera preceder) cualquier actividad de construir; y podemos agregar que esta relación sólo se articulará en diferenciaciones histórico-culturales (como lo ilustra Heidegger con el ejemplo de las casas de campesinos de la Selva Negra, cerca de Friburgo donde vivía). Mirando Chile como "el fin del mundo", el enfoque de Heidegger nos permite comprender el fenómeno en cuestión como una modalidad específica de habitar. Para captar su significado complejo (pero sobre todo implícito), intentaré concentrarme, de manera genealógica y apuntando a ciertos autores paradigmáticos, sobre momentos claves en la relación ("habitar") con el espacio proto-nacional y luego nacional chileno. Mi objetivo es trazar una trayectoria que, a lo largo de los siglos, se ha convertido en un aspecto (y tal vez incluso la matriz) de la identidad cultural de Chile. 
Para inaugurar esta genealogía chilena con la posición de un observador histórico ubicado fuera de Chile, quisiera invocar brevemente los Comentarios reales, del Inca Garcilaso, porque el enfoque articulado por este hijo de una princesa inca y un conquistador español respecto del continente sudamericano y sus culturas precoloniales acabó brindando una premisa fundacional conjunta para las posteriores identidades nacionales divergentes en América Latina. La principal preocupación del Inca era mostrar e incluso defender que el "mundo recién descubierto" era parte de la única creación emprendida por el Dios cristiano, y que éste tenía su propio lugar dentro de las siguientes etapas de revelación a través de las cuales Dios les había dado y seguiría dándoles a los humanos visiones respecto de su cuidado y sus planes.

Es, por ende, adecuado afirmar que el Inca consideraba el conocimiento sobre las diferentes provincias acumuladas por el imperio inca y cada paso futuro de "descubrimiento" de lo que hasta entonces eran "regiones oscuras" (que, para él, correspondían a todas las regiones al sur del desierto de Atacama) como modalidades de la revelación divina, de una revelación divina que los seres humanos tenían que esperar y luego descubrir con serenidad y paciencia. Si bien el nombre "Chile" muy probablemente proviene de un vocablo inca que significa "fin del mundo", el Inca Garcilaso era escéptico respecto de las creencias de su tiempo según las cuales esa parte del continente (de cuya geografía él tenía una visión muy precisa) sería inhabitable; porque esa condición sería incompatible con su premisa teológica respecto al cuidado que el Dios Creador daba a todos los seres humanos.

El poema épico La Araucana, de Alonso de Ercilla, que circuló en España un par de décadas antes, durante el siglo dieciséis, ilustra la experiencia inmediata de su autor en aquella colonia austral del imperio. Contiene observaciones y connotaciones muy diferentes de las invocadas por el Inca Garcilaso y, sin embargo, no es incompatible con su concepción mucho más teológica. El texto de Ercilla pertenece a un género de épica de la primera modernidad, en el cual la alabanza explícita de la victoria sobre un enemigo poderoso e "indómito" se acaba transformando en la evocación de una imagen casi sagrada del enemigo y en una visión más bien crítica de la propia nación y sus representantes; lo que explica por qué tantos temas e incluso nombres del texto de Ercilla se transformaron en una matriz para la autoimagen nacional de 
Chile tal como surgió durante el siglo XIX y comienzos del siglo XX. En una secuencia interminable de estrofas (y, una vez más, con un marco geográfico sorprendentemente preciso) describe la bravura militar de los araucanos, (la imaginación de) su estructura social y política no jerárquica que no incluía a un rey o una familia real y la tenacidad con que contraatacaron de manera bastante regular recuperando territorios antes perdidos por el avance de las tropas españolas. En cambio, el conquistador Pedro de Valdivia aparece como un personaje, en el mejor de los casos, ambiguo. Si bien demostró poseer visión militar y económica en algunas situaciones, Ercilla no dejó duda de que Valdivia toleraba de manera rutinaria la corrupción y la codicia entre sus tropas, lo que se tradujo en actitudes deleznables de falta de respeto hacia los nativos. Para cualquier persona familiarizada con este texto y con el tono con el que los chilenos hablan sobre sí mismos hasta hoy, es obvio que sus motivos centrales han dejado una huella duradera (y, por ende, a estas alturas, en gran parte anónima) en la autoimagen nacional.

\section{$* * * *$}

En 1807, el aristócrata prusiano, oficial de artillería, administrador e intelectual romántico Heinrich von Kleist publicó su breve narración El terremoto en Chile (Das Erdbeben in Chili), en la cual, aparte de evidenciar - él también - un conocimiento detallado del paisaje que rodea la ciudad de Santiago (aparentemente disponible en el norte de Alemania incluso antes de las descripciones geográficas de Alexander von Humboldt), da cuenta de una visión europea sobre Chile previa al evento político de la Independencia, una imagen que parece muy compatible con los tonos de la epopeya de Ercilla. Pero Kleist nunca había visitado el país ni, por lo que sabemos, había tenido contacto alguno con los escasos europeos contemporáneos que habían contemplado esas tierras con sus propios ojos y luego regresado. La inspiración literaria detrás de su breve texto, considerado como un clásico de todos los tiempos de la literatura alemana, fue una novela de 1777 del autor francés Jean-François Marmontel, que narra la magna destrucción cultural causada en el Perú por el terremoto de 1647. Si bien no estamos seguros de por qué Kleist traslada el lugar de la acción de Perú a Chile como la colonia más austral, queda claro que asoció un fervor religioso específico a esta ubicación geográfi- 
ca, ilustrado por las reacciones de varios predicadores ante la catástrofe "en ese remoto rincón del mundo", fervor que puede haber correspondido más bien a una proyección del autor, de formación luterana, que a una realidad palpable de Santiago en aquel período histórico.

Por otra parte, el texto de Kleist destaca, quizás por primera vez en términos cronológicos, una temática que luego se convertiría en parte de una visión literaria de la cultura y la geografía de Chile entre varios autores que, con certeza, no estaban familiarizados con Kleist. Es el motivo de una bucólica - y en el contexto histórico de las revoluciones burguesas, deberíamos agregar, utópicas - noche de felicidad y mutuos cuidados entre los sobrevivientes del terremoto (en una primera instancia vivido como un "fin del mundo" temporal), escenificada en un valle de los alrededores de Santiago; una noche comunitaria que sobreviene al día del desastre natural y que, al mismo tiempo, precede a la violenta venganza colectiva contra aquellos considerados culpables de haber provocado, por sus pecados carnales, el terremoto como un castigo divino. Lo que me interesa aquí es el ("cuasi dialéctico") contraste entre un evento experimentado como el "fin del mundo" en el extremo geográfico del planeta y la aparición de un nuevo comienzo fundacional surgido desde el mismo espacio.

\section{$* * * *$}

Otra forastera, María Graham, quien a sus treinta y seis años arribó a Valparaíso en 1821 después de cruzar el Cabo de Hornos y perder a su marido en esa travesía, permaneció durante un año en la joven República de Chile y redactó una serie de apuntes (que después serían publicados en libro) con observaciones detalladas sobre el lugar y sus habitantes. Las notas de María Graham marcan el inicio de una nueva y decisiva etapa en el surgimiento de una identidad chilena moldeada por su geografía. Ella escribe un capítulo secular de aquella revelación progresiva - a través del descubrimiento - que el Inca Garcilaso había relatado después de 1600 , puesto que los contenidos de su diario se basan en prácticas, conversaciones y percepciones cotidianas más que en proyecciones teológicas, épicas o utópicas.

$\mathrm{Su}$ primera impresión del país es claramente estética. Califica como "majestuosa" la visión de la cordillera de los Andes "que cuelga 
sobre el océano", apartándose del enfoque racional y, por tanto, analítico, que predominaba en el interés británico por las nuevas naciones sudamericanas. Pero, tras su decisión de permanecer en Chile por un tiempo, María Graham tampoco abandona un interés más realista por el lugar. Éste se manifiesta, por ejemplo, cuando califica el territorio ubicado al este de Valparaíso como un "plano, arenoso y fértil", o cuando señala, en reiteradas oportunidades, que la belleza del paisaje chileno tiende a "pasar desapercibida" tras apreciaciones sobre su valor agrícola.

Varias descripciones de los habitantes de Chile en el diario de María Graham muestran la misma estructura. Cuando narra sus impresiones sobre una recepción en los círculos de la alta sociedad santiaguina, se refiere en términos elogiosos a las mujeres presentes, calificándolas como "las más bellas del mundo"; sin embargo, insiste en cuánto distan de la sofisticación europea en su atuendo y forma de expresarse. Utiliza de manera reiterada el adjetivo "amables" al referirse a los campesinos con los que le ha tocado interactuar, y el mismo vocablo aparece en sus notas sobre una conversación personal con Bernardo O'Higgins, cuya sinceridad y genuina preocupación por su pueblo le suscitan admiración, lo que no le impide hacer notar su baja estatura y sobrepeso. Sin embargo, esta experiencia le permite más adelante establecer un contraste positivo frente al libertador argentino José de San Martín, a quien María Graham conoció personalmente y cuya elegancia le hizo dudar acerca de la sinceridad de sus intenciones y acciones políticas.

Sus visiones y juicios parecen reacciones tempranas ante un estilo cultural que estaba en vías de conformarse como algo propiamente chileno, y, sin embargo, no podía dejar de parecer paradójico cuando era observado desde afuera. Las mujeres de Santiago le parecían hermosas a María Graham pese a considerar muy banal su comportamiento (utiliza el término "gracia" — grace - para dar cuenta de esa ambigüedad), los campesinos y los políticos eran "amables" a pesar de que a éstos no les preocupaba en absoluto cómo eran percibidos, y la belleza de la tierra solía impresionar a quienes la contemplaban, aun cuando lo hacían con un trasfondo de interés agrícola.

Hay que insistir que esta forma de experiencia reiterada y levemente paradójica fue una respuesta al entorno chileno desde la perspectiva de una mentalidad británica (la de María Graham), dentro de la cual la 
racionalidad pragmática se había impuesto desde hacía mucho tiempo. Por el contrario, la forma de habitar propiamente chilena puede que nunca haya alcanzado esta escisión entre una actitud racional (pragmática) y una estética (corpórea) hacia el espacio al "fin del mundo". En el siglo XIX intelectuales chilenos comenzaban a descubrir las posibles "raíces" en la relación con el territorio nacional en la resistencia y tenacidad de los araucanos que la crónica de Alonso de Ercilla había alabado, pero puede que nunca hayan surgido, hasta hoy, modos separadamente prácticos o estéticos de experimentar el entorno nacional. Es probable que esta visión explique la fuerte y famosamente popular resonancia de los dos versos finales en el poema "Chile" de Nicanor Parra, publicado por primera vez en 1968: “Creemos ser país / y la verdad es que somos apenas paisaje". En la voz de un autor que redobla el efecto de un tono nacional de modestia al rehuir de cualquier refinamiento lírico y tratar de constituirse en antipoeta, la nación como "país" se transforma en "apenas paisaje". Pero esto también significa que en la inmediatez del "paisaje" como experiencia corpórea del espacio aparece el elemento indispensable e integral de una identidad nacional que nunca distingue entre su componente pragmático y su componente estético.

Es muy probable que esta no separación propiamente chilena entre dos modos de relación con el espacio nacional sea lo que haya irritado y confundido a Ernesto Grassi 130 años después de María Graham. Aún más importante es señalar que, como estilo y gesto de identidad cultural, funciona, en primer lugar, de manera homogénea (sólo para una visión exterior parecerá paradójica) y que se articula, en segundo lugar, más como una matriz de comportamientos y experiencias que como un rango específico de contenidos o valores. En otras palabras: la modalidad particular de habitar el espacio en el fin del mundo ha constituido la dimensión central de la identidad cultural de Chile, al proporcionar una base difícil de captar para un tipo específico de rituales, coreografías y tonos que identificamos como nacionales.

$* * * *$

Si se compara esta tonalidad con los acentos altisonantes y exaltados de los discursos autorreferentes de otros países (especialmente en América del Sur), bien puede ser que la inseparabilidad entre una 
relación pragmática y estética explique la sobriedad distintiva que ha caracterizado por larga data el estilo cultural de Chile. No hay discurso literario que haya capturado, hecho presente y develado este tono en forma más natural y bella, en un modo "menor", que los poemas de Gabriela Mistral de mediados del siglo XX. No sería raro que adquieran una nueva resonancia en el actual clima global de entropía sin brújula y de un futuro sin alternativas. Con el propósito de tratar de mostrar cómo la simultaneidad de una actitud estética y pragmática hacia la tierra fue la base y la matriz de su escritura (y también con el objetivo de transmitir la delicada prosodia de sus textos, que, por lo demás, no debe ser pasada por alto en una lectura silenciosa), inicio mi comentario sobre los motivos que hicieron que Mistral se transformara en una presencia viviente de la cultura nacional citando las cinco estrofas completas de su poema "Tierra chilena":

Danzamos en tierra chilena, más bella que Lía y Raquel; la tierra que amasa a los hombres de labios y pechos sin hiel...

La tierra más verde de huertos, la tierra más rubia de mies, la tierra más roja de viñas, ¡qué dulce que roza los pies!

Su polvo hizo nuestras mejillas, su río hizo nuestro reír, y besa los pies de la ronda que la hace cual madre gemir.

Es bella, y por bella queremos sus pastos de rondas albear; es libre y por libre deseamos su rostro de cantos bañar...

Mañana abriremos sus rocas, la haremos viñedo y pomar; mañana alzaremos sus pueblos; ¡hoy sólo queremos danzar! 
Las personas "de labios y pechos sin hiel", incluso en medio de sus danzas alegres y cantos festivos, nunca pierden contacto con la tierra, el polvo y las rocas, ni tampoco con la explotación de la naturaleza ni la intensidad de las emociones políticas de los "pueblos" (como se menciona en la estrofa final).

Más que cualquier otro poeta chileno antes o después de ella, y en virtud de su profesión como maestra de escuela primaria que la llevó a los extremos sur y norte del territorio nacional, Gabriela Mistral halló imágenes para las diferentes regiones del país que se han convertido en un componente natural del patrimonio cultural colectivo. Por ejemplo, la estrofa inicial de "Desolación", el primer poema de sus Paisajes de la Patagonia, evoca, en su permanente espesor, la niebla que envuelve la existencia de quien arriba al extremo sur:

La bruma espesa, eterna, para que olvide dónde me ha arrojado la mar en su ola de salmuera la tierra a la que vine no tiene primavera: tiene su noche larga que cual madre me esconde.

Sin embargo, la certeza de haber llegado a un final, al fin del mundo, nunca detendrá o absorberá la energía de un movimiento horizontal que empuja a ir aún más lejos. Sólo los muertos han "ido" a ese lugar para observar "un mar callado y yerto / crecer entre sus brazos":
¿A quién podrá llamar la que hasta aquí ha venido si más lejos que ella sólo fueron los muertos?
¡Tan sólo ellos contemplan un mar callado y yerto crecer entre sus brazos y los brazos queridos!

La grisura y el frío nunca cesarán. Pero una energía responderá a la energía que empuja a los muertos más allá del límite de la vida humana, y esta energía es "el mar callado y yerto que crece". Una vez más, al igual que en la noche utópica de Kleist que siguió al día de la destrucción final, el fin del mundo se transforma en un nuevo comienzo. Son comienzos dubitativos, difíciles de percibir y distinguir: "hablan extrañas lenguas y no la conmovida / lengua que en tierra de oro mi vieja madre canta". Estas "extrañas lenguas" apenas nos alcanzan, pero cuando lo hacen golpean como un "destino" inclemente y sin piedad. Sin embargo, "Desolación" concluye con un comienzo envuelto en nieve: 
Siempre ella, silenciosa, como la gran mirada

de Dios sobre mí; siempre su azahar sobre mi casa;

siempre como el destino que ni mengua ni pasa,

descenderá a cubrirme, terrible y extasiada.

La palabra "Dios" no debe confundirnos en este caso, ya que Gabriela Mistral nunca se rinde a la fascinación de una trascendencia religiosa. La presencia de Dios es una presencia "como si" ("como la gran mirada / de Dios"), la presencia de una metáfora que representa la nieve y, sobre todo, la energía que cubre.

En sus poemas sobre el Norte del país, como el extremo opuesto del territorio nacional, Mistral vuelve a lidiar con fuerzas que trascienden la existencia humana, pero éstas conforman una topología muy diferente. En términos pragmáticos y económicos, el Norte es la tierra de los metales y, por ende, la fuente de la riqueza y el posible bienestar de Chile. El fuego es el primero en "redimir" el cobre (en un poema que lleva su nombre) de "las piedras que eran sus madres":

Están redimiendo el cobre

con las virtudes del fuego.

De allí va a salir hermoso

como nunca se lo vieron

las piedras que eran sus madres.

De nuevo se produce una interesante tensión entre connotaciones potencialmente religiosas y significados pragmáticos en esta estrofa. En cualquier contexto cristiano la palabra "redención" invoca un horizonte teológico, pero también resulta claro que es utilizada aquí en una acepción estrictamente técnico-práctica. A diferencia del movimiento horizontal que empuja más allá del límite austral, los metales redimidos del Norte desencadenan una energía de elevación vertical:

Suba el Padre Cobre, suba, que naciste para el fuego y te pareces a él en el fervor de tu pecho.

Todavía, todavía no confiesas el secreto 
del amor y de la fiebre

que está en tus piedras gimiendo.

Nadie te habrá dicho hermoso,

porque el pecho no te vieron.

Pero, así como el "Dios" del Sur resultó ser una metáfora para la energía cubierta por la nieve, la personificación del Cobre ("Padre Cobre") acaba siendo la alegoría de un poder que nunca dialogará con los seres humanos. Cabe pensar que las palabras e imágenes de Gabriela Mistral le han brindado a la identidad cultural de Chile su propio equivalente de un horizonte metafísico. Como corresponde a una nación cuyos gestos y tonos son los de la sobriedad que casi nunca abandona su relación práctica con el espacio y la tierra, este horizonte es "metafísica sin "meta", es la metafísica de diferentes energías que nunca trascienden la concreción de la vida humana y su entorno material específico. Invocada y condensada en los poemas de Gabriela Mistral es efectivamente una metafísica en "clave menor".

La mayoría de estos motivos nacionales vuelven en los textos de Pablo Neruda, en especial en los poemas de su Canto general dedicados a Chile, y durante el tercer cuarto del siglo XX, cuando Neruda surge tal vez como la figura internacional más visible y contundente de la inspiración poética, alcanzando un grado de resonancia y admiración internacional que Gabriela Mistral nunca obtuvo. Si, con la distancia que nos da el tiempo, nos preguntamos por las razones de esa diferencia, el problema nos lleva a la voluntad (por no decir, la ambición) de Neruda de integrar chispazos poéticos e intuiciones en el marco más general de una visión histórica del mundo explícita, la del materialismo dialéctico, por supuesto, que, como monismo filosófico, tenía su propia forma de eludir cualquier "más allá" metafísico o trascendental. Personalmente, y en esta etapa de mi vida — nací en 1948_, siento una conexión mucho más inmediata con las intuiciones dubitativas de Mistral que con los versos a ratos excesivamente ampulosos de Neruda, tanto en mis reacciones como extranjero - al espacio de Chile y en mis relaciones más generales e individuales con el mundo material. Pero nada de esto pone en tela de juicio las conocidas y alabadas contribuciones de Neruda a la identidad cultural de Chile, ni la belleza de muchos de sus poemas, en particular aquellos que no explicitan su marco ideológico, como la invocación de la "Patagonia" en la sexta parte del Canto general: 
Las focas están pariendo

en la profundidad de las zonas heladas, en las crepusculares grutas que forman los últimos hocicos del océano, las vacas de la Patagonia se destacan del día como un tumulto, como un vapor pesado que levanta en el frío su caliente columna hacia las soledades.

Desierta eres, América, como una campana: llena por dentro de un canto que no se eleva, el pastor, el llanero, el pescador no tienen una mano, ni una oreja, ni un piano, ni una mejilla cerca: la luna los vigila, la extensión los aumenta, la noche los acecha, y un viejo día lento como los otros, nace.

Estas imágenes comparten, en su tonalidad y con sus colores específicos, la visión de Gabriela Mistral del extremo sur del mundo como un fin de la vida. Como lector actual, agradezco el rechazo del poeta a dejar que el posible canto "se eleve" (en el segundo verso de la segunda estrofa), a pesar de que estoy totalmente consciente de que, en el contexto histórico de Neruda y en el marco más amplio del Canto general, el aplazamiento es sólo consecuencia de la posición histórico-mitológica de este poema en particular, en una etapa previa de la evolución que Neruda quería narrar; se trata, en efecto de una manifestación "no aún realizada" del canto. Pero más allá de esa idea, hay una explícita anticipación según la cual esta latencia - temporal - algún día se transformará en el inicio de la historia en otro de esos ciclos dialécticos que hemos identificado, al menos un comienzo de la historia del continente americano.

La relación entre Neruda y Mistral, en sus evocaciones del Norte de Chile, es bastante similar. Sobre todo, convergen en mencionar los minerales de esta región como un potencial para movimientos de energía vertical que nunca trascienden el mundo material. Pero aparte de compartir una "metafísica sin "meta", las alegorías de Neruda están a veces moldeadas por una narrativa evolutiva más amplia. En la se- 
cuencia introductoria del Canto general ("La lámpara en la tierra”), por ejemplo, la "madre de los metales" (¿mercurio?) aparece como mártir de la explotación:

Madre de los metales, te quemaron,

te mordieron, te martirizaron,

te corroyeron, te pudrieron

más tarde, cuando los ídolos

ya no pudieron defenderte.

$\mathrm{Y}$ en el mismo poema el cobre parece estar aguardando un destino que aún no llega:

El cobre establece sus crímenes

en las tinieblas insepultas

cargadas de materia verde,

y en el silencio acumulado

duermen las momias destructoras.

Galardonados ambos con el Premio Nobel de Literatura en 1945 y 1971, respectivamente, Gabriela Mistral y Pablo Neruda le dieron a la literatura y a toda la cultura chilena una visibilidad internacional que no ha menguado desde entonces. $\mathrm{Y}$, sin embargo, su rol verdaderamente fundacional en la identidad cultural de la nación se manifiesta por sobre todo en las imágenes y topologías con que agruparon $y$ confirieron nuevas formas a una serie de motivos antes inconexos sobre la forma específica de habitar el espacio del país.

En nuestros días — al menos es mi impresión desde afuera—, crece la sospecha de que el referente chileno relacionado con el "fin del mundo", con toda su vaguedad, se haya vuelto obsoleto. La calma (2005), esa magnífica narración de Sergio Missana sobre la Patagonia, se inscribe en la tradición de la novela histórica. Situada a comienzos del siglo XX, cuenta la historia del secuestro de una niña autista por su padrastro, quien trata de evitar que su hija viva en un hospital psiquiátrico estatal. La escena decisiva transcurre en un pueblo sin nombre de la región más austral, y lentamente describe la "calma lúcida" con la que el héroe por 
sí solo logra neutralizar a un grupo de agentes del Estado que lo persiguen. A la vez que este episodio vuelve a evocar el motivo de la energía que surge del más absoluto "fin del mundo", también vemos una vez más cómo las decisiones estratégicas nunca están separadas de la relación sensual de los protagonistas con las llanuras y montañas infinitas y sublimes a través de las cuales escapan.

En un ensayo titulado Regreso a esa Patagonia, publicado cinco años antes de La calma, de Missana, Francisco Coloane especula sobre las posibles razones que expliquen que el sentimiento nacional específico de una relación con "el fin del mundo" finalmente se haya desvanecido:

La Patagonia de hoy es una realidad distinta a la de ayer, trágica y romántica. Quedan pocas grandes estancias. La otrora potencia industrial comercial que se percibía parece desvanecerse con un progreso incomprensible. La Tierra del Fuego, que se desarrollaba con su petróleo, su planta de refinación, sus perspectivas de futuro, está anclada hoy a una imagen forjada por su propia belleza. Tal vez, progreso y belleza no puedan navegar juntos sin que los medie un naufragio.

La negativa de Coloane de aceptar y relacionarse con un Sur que ha pasado a ser valorado de manera predominante (si no exclusiva) por sus hermosos paisajes parece confirmar nuestra tesis de que los aspectos prácticos y estéticos nunca se habían separado en la forma chilena tradicional de habitar. Incluso cuando divergen - esto es lo que la última cita parece sugerir - no dejan de transformarse en la impresión de una simultaneidad paradójica.

Algunos de los mejores poemas de Jorge Teillier pueden leerse como un antídoto contra este miedo a una pérdida histórica. Alzándose contra el recurrente motivo del fin temporal del mundo, "La última isla" describe ámbitos de la naturaleza y comportamientos que ignoran cualquier cambio:

De nuevo sólo se escucha el crepitar inextinguible de la lluvia que cae y cae sin saber por qué, parecida a la anciana solitaria que sigue tejiendo y tejiendo; 
y se quiere huir hacia un pueblo

donde un trompo todavía no se deja girar

esperando que yo lo recoja,

pero donde se ponen los pies

desaparecen los caminos,

y es mejor quedarse inmóvil en este cuarto

pues quizá ha llegado el término del mundo.

De una forma más directa y drástica que en estos versos, el fin temporal del mundo (y la libertad de ignorarlo) se invoca en el poema "Fin del mundo". Resulta ser un día como cualquier otro, cuando nada se aparta de las reglas cotidianas:

El día del fin del mundo

será limpio y ordenado

como el cuaderno del mejor alumno.

El borracho del pueblo

dormirá en una zanja,

el tren expreso pasará

sin detenerse en la estación (...)

¿Pero por qué el tiempo, incluido el último día del mundo, no logra tener un efecto transformador en nosotros? Podríamos afirmar que Teillier tenía una idea temprana del fin de la visión histórica del mundo tan invocada en nuestros días. Pero al mismo tiempo los últimos versos de "Fin del mundo" apuntan a los movimientos inmutables de la naturaleza como una presencia que vuelve imposible el fin del tiempo:

Y yo diré: "El mundo no puede terminar porque las palomas y los gorriones siguen peleando por la avena en el patio".

$* * * *$

No cabe duda de que Chile ha realizado, y probablemente concluido de manera definitiva, desde finales del siglo XIX aquel proceso de autodescubrimiento en tanto espacio geográfico y cultural que el Inca 
Garcilaso había descrito y anticipado como un tipo de revelación divina. Dentro de este mismo proceso surgió una forma propiamente nacional de habitar que, en lugar de producir imágenes y conceptos explícitos de identidad, se ha vuelto sobre todo la base para una serie de actitudes y comportamientos colectivos, cuyo denominador común parece ser un escepticismo juicioso y sobrio respecto de la elevación metafísica y la autonomía estética; un escepticismo a veces acompañado de una idea según la cual un destino enérgico y un nuevo comienzo podrían surgir en situaciones próximas a un final. Cuando los chilenos hablan sobre su país y sobre ellos mismos como el "fin del mundo" se refieren, a menudo de manera casi inconsciente, a este mismo síndrome, cuyo estilo y gesto han sido, a lo largo de más de dos siglos, una matriz sólida y flexible de comportamientos y autoimágenes para la nación.

¿Pero es posible que una matriz como ésta se pueda marginar de la historia según, entre otros, parece sugerirlo Jorge Teillier en algunos de sus poemas? Hay buenas razones para no excluir de entrada la posibilidad de una excepción de la historia. Una es que, como ya dijimos, quizá hayamos simplemente llegado al final de la visión histórica del mundo como un paradigma global dominante, cuyo dogma básico era que el cambio y la transformación continuos eran inevitables para cualquier tipo de fenómeno. Si podemos asumir, como una segunda razón, que la identidad cultural chilena está en efecto relacionada principalmente con el espacio, parece plausible asumir su — relativa — independencia de los poderes transformadores del tiempo, incluso dentro de la visión histórica del mundo. Sobre todo, Chile vive y ha vivido bastante bien su propia forma de habitar como núcleo y matriz de su identidad cultural. La nación ciertamente no necesita preocuparse por exhortaciones condescendientes en nombre de la Historia o seguir tradiciones intelectuales esfumadas hace años como las de Ernesto Grassi o Juan Rivano. En definitiva, pensar en Chile como "el fin del mundo" constituye una fórmula espléndida de aislamiento y singularidad. EP 